competencies across specialties for working in niche super-specialised areas. Any such provision needs to be

education \& training structured to protect the value of the CCT and should have the quality assurance processes of pre-CCT training posts. Post-CCT training should not dilute the increasing importance of continuing professional development within the consultant grade.

\section{Conclusion}

It is clear that there are specialty combinations that remain crucial to service provision and appropriate training must therefore exist to ensure that there are specialists in these areas. However, traditional dual training appears to be under threat and adaptations need to be made to the new structure of postgraduate training to allow trainees to develop the necessary competencies across specialties. The rhetoric surrounding MMC promised greater flexibility of training and it is of paramount importance that this is developed in order for trainees to achieve the broad and diverse range of competencies that are required by these developing services. This will allow us to meet the needs of our patients and deliver the best possible care.

\section{Acknowledgements}

We thank Paul O'Connor for collating the information from the College membership database.

\section{Declaration of interest}

C.O. is the Chair and O.W. is the immediate past Chair of the Psychiatric Trainees' Committee of the Royal College of Psychiatrists. O.W. is a Specialist Registrar undertaking dual training in Child and Adolescent and Forensic Psychiatry. S.B. is the Registrar of the Royal College of Psychiatrists and a Professor of Child and Adolescent Forensic Mental Health.

\section{References}
1 PretoriusW, Goldbeck R. Survey of psychotherapy experience and interest among psychiatric specialist registrars. Psychiatr Bull 2006; 30: 223-5.
2 Allen R, Butler R. Trainees' attitudes to single and dual training in old age psychiatry. Psychiatr Bull 2001; 25: 471-2.
3 Department of Health. The National Service Framework for Mental Health. Modern Standards and Service Models. Department of Health, 1999
4 Department Of Health. A Reference Guide for Postgraduate Specialty
Training in the UK (The Gold Guide). Department of Health, 2008 (http://www.mmc.nhs.uk/ pdf/Gold\%20Guide $\% 202008 \%$ 20-\%20FINAL.pdf).
5 Royal College of Psychiatrists. A Competency Based Curriculum for Specialist Training in Psychiatry. Royal College of Psychiatrists, 2006 (http://www.rcpsych.ac.uk/ docs/Curriculum\%20-\%20core $\% 20$ and\%20general\%20module. doc).
6 Allington-Smith P. Mental health of children with learning disabilities. Advan Psychiatr Treat 2006; 12 $130-8$.

*Clare Oakley Specialty Registrar, Reaside Clinic, Birmingham Great Park, Bristol Road South, Rubery, Birmingham B45 9BE, email: clareoakley@doctors. org.uk, OllieWhite Specialist Registrar, Highfield Adolescent Unit, Warneford Hospital, Oxford, Sue Bailey Professor of Child \& Adolescent Forensic Mental Health, University of Central Lancashire, Adolescent Forensic Service, Manchester

\title{
Mental Capacity Act 2005: views and experiences of learning disability psychiatrists
}

\author{
AIMS AND METHOD \\ Postal questionnaires were sent \\ out to 66 learning disability \\ psychiatrists to assess their \\ knowledge and experience of the \\ Mental Capacity Act 2005. \\ RESULTS \\ A response rate of $55 \%(n=36)$ was \\ achieved; $22(61 \%)$ respondents felt \\ that patient care had improved; \\ $16(44 \%)$ felt workload had
}

\author{
increased. Despite $79 \%(n=23)$ of \\ the respondents feeling that the \\ training for the Act was adequate, \\ only $19 \%(n=7)$ were aware of the \\ situations where patients had to be \\ referred to the Independent Mental \\ Capacity Advocate (IMCA) service \\ and only $53 \%(n=19)$ were aware \\ that the Act currently does not cover \\ patients who fall in the 'Bournewood \\ gap'.
}

\begin{abstract}
CLINICAL IMPLICATIONS
Learning disability psychiatrists are still not conversant with significant parts of the Act and this raises questions about the adequacy of the training delivered. Implementing the Act should improve patient care but will have implications for the workload of professionals.
\end{abstract}

Mental capacity is the ability of an individual to take decisions that influence an individual's life. Decisionmaking might vary from simple issues to decide what to eat or wear, to more complex ones about deciding on receiving or refusing medical treatment. It is presumed that by early adulthood every individual gains capacity and this remains throughout life unless demonstrated to be lost permanently such as in people with severe intellectual disability and dementia, or temporarily as in acute confusional state.

In England and Wales, the Mental Capacity Act 2005 provides a statutory framework for adults (aged 16 years or older) who are unable to make decisions for themselves. The Act has been implemented in a piecemeal fashion. In April 2007, the new Independent Mental Capacity Advocate (IMCA) service became operational in 
England only. All other parts of the Act, including IMCAs in Wales, came into force in October 2007. The Code of Practice ${ }^{1}$ provides guidance about implementing the Act. Clinicians are legally required to 'have regard to' relevant guidance in the Code of Practice.

Most of the Act confirms and reinforces best practice, and codifies the pre-existing common law provisions. However, there have been significant changes that have been introduced. One of the innovations of the Act is the development of an independent advocacy scheme to support particularly vulnerable incapacitated adults. The Code of Practice has specified that an IMCA must be instructed and consulted for patients who have no one to support them, other than paid staff when serious medical treatment is being proposed or there are proposals to arrange or change accommodation in hospital and/or a care home. An IMCA may be instructed to support someone who lacks capacity when decisions are made regarding care reviews when no one else is available to consult. Irrespective of whether family or friends are involved, IMCAs may be instructed for adult protection cases. The National Health Service or local authorities have a statutory requirement to consult the advocacy services and are deemed to be the 'responsible body' in these circumstances. The Act has introduced two new criminal offences: ill treatment and wilful neglect for violating the statutory recommendations of the Mental Capacity Act.

Protecting the rights of in-patients who lack capacity to consent and adhere to treatment was highlighted in the Bournewood case ( $L$ v. Bournewood Community and Mental Health NHS Trust [1998]). ${ }^{2}$ The case concerned a man with autism with severe intellectual disabilities who was informally admitted to Bournewood Hospital under common law. The European Court of Human Rights in its judgment $(H L \text { v. UK [2004]) })^{3}$ found that he had been deprived of his liberty unlawfully without a legal procedure with safeguards and rapid access to a Court of Appeal. The Act makes it clear that it is unlawful under the Act to deprive a person of their liberty within the meaning of Article 5(1) of the European Convention on Human Rights.

The Mental Capacity Act currently does not have the provision to deal with such adherent incapacitated patients. However, the new Mental Health Act 2007 will modify the Mental Capacity Act, which will be used as a vehicle for introducing deprivation of liberty safeguards. The new Mental Health Act 2007 will be implemented from 1 April 2009. In the interim period the Department of Health has issued guidelines for procedural safeguards for protection of this subset of patients. ${ }^{4}$

\section{Method}

We designed a questionnaire consisting of ten questions to ascertain the knowledge and experiences of learning disability psychiatrists about the Act. The questionnaire was anonymous but we asked for basic demographic information on grade and the work place.

Learning disability psychiatrists (consultants, specialist registrars, and staff grades and associate specialists) working in the region of the Eastern Deanery (Essex, Middlesex, Hertfordshire, Bedfordshire, Cambridgeshire and Norfolk) and in the Ridgeway Partnership Trust (counties of Oxfordshire, Berkshire, Buckinghamshire, Wiltshire and Swindon) were approached. Questionnaires were not sent out to junior trainees as it was felt they would not have enough experience in the specialty to respond to the questionnaire. In total, 66 postal questionnaires were sent out in December 2007.

\section{Results}

Out of 66 questionnaires sent out, 36 were returned, a response rate of $55 \%$. Out of these, 35 respondents identified their grades: 22 consultants, 9 specialist registrars and 4 staff grades and associate specialists. Fifteen of the respondents worked in the Eastern Deanery, 10 in the Ridgeway Partnership Trust and 11 did not specify their place of work. The results from the questionnaires are summarised in Table 1.

\section{Discussion}

In accordance with the guidance issued by the British Medical Association, ${ }^{5}$ all doctors working with adults who lack, or who may lack, capacity need to be familiar with the underlying principles and the basic provisions of the Act. Previous surveys indicate that clinicians have limited understanding of the law pertaining to capacity. 6,7 Twenty-nine (81\%) doctors in our survey indicated that they had received training about the Act, of which 23 (79\%) felt that the training was adequate. Despite this, a startling and rather worrying revelation of our survey was that only seven $(19 \%)$ respondents were aware of the exact criteria where 'unbefriended' incapacitous individuals must be referred to the IMCA service. This gap in knowledge can potentially have serious legal ramifications, as referral to the IMCA service is a statutory obligation. This also raises the question whether there are other gaps in knowledge in other areas of the Act not explored in this survey.

With the new Act, capacity has to be assessed in relation to a specific decision. This is described as a 'functional' approach as opposed to a 'status' approach where a person having reached a diagnostic threshold would be described as lacking capacity for all decisions. This has major implications, as capacity would need to be assessed in every situation. A study ${ }^{8}$ revealed that requests for capacity assessments are mostly reactive (patients refusing management suggested by the clinical team) rather than pro-active. This practice is bound to change with the implementation of the Act. This is expected to increase the workload of professionals as the quantity of capacity assessments would increase. Twenty-eight (78\%) of the respondents in our survey revealed that they had been involved in capacity assessments ranging around both physical and mental illness treatment to social issues regarding accommodation changes, finances and other matters since the implementation of the Act. Despite this, surprisingly only 
education \& training

\begin{tabular}{|c|c|c|c|}
\hline Questions on Mental Capacity Act 2005 & $\begin{array}{c}\text { Yes } \\
\text { n (\%) }\end{array}$ & $\begin{array}{c}\text { No } \\
n(\%)\end{array}$ & $\begin{array}{c}\text { Unsure } \\
n(\%)\end{array}$ \\
\hline 1. Did you receive any training for the Act? & $29(81)$ & $7(19)$ & \\
\hline 2. If yes, did you feel the training was adequate? & $23(79)$ & $6(21)$ & \\
\hline 3. Has the Act changed your practice in any way? & $32(89)$ & $4(11)$ & \\
\hline 4. Following the implementation of the Act have you had to assess capacity in any situation? & $28(78)$ & $8(22)$ & \\
\hline 5. Do you think your workload has increased since the implementation of the Act? & $16(44)$ & $18(50)$ & $2(6)$ \\
\hline 6. Do you think patient care has improved since the implementation of the Act? & $22(61)$ & $9(25)$ & $5(14)$ \\
\hline 7. Is there an integral process for a referral to the IMCA to be made where you are working? & $22(61)$ & $9(25)$ & $5(14)$ \\
\hline 8. Are you aware of the situation where IMCA has to be involved? & $7(19)$ & $29(81)$ & \\
\hline 9. Are you aware of the situations where IMCA might be involved? & $8(22)$ & $28(78)$ & \\
\hline 10. Do you think the Act presently covers patients who fall within the Bournewood gap? & $14(39)$ & $19(53)$ & $3(8)$ \\
\hline
\end{tabular}

IMCA, Independent Mental Capacity Advocate.
$16(44 \%)$ of the doctors felt that their workload had increased.

Improvement in patient care was a positive experience indicated by $61 \%$ (21) of the respondents. Some examples of good practice revealed by the respondents were more multidisciplinary involvement, increased IMCA service involvement, greater awareness of legal and ethical issues and improved documentation.

Only $19(53 \%)$ of the respondents in our study were aware of the fact that the Act as it currently stands does not cover patients who lack capacity and adhere to treatment but are admitted informally to in-patient units - the 'Bournewood gap'. There is limited knowledge about the prevalence of mental capacity among psychiatric in-patients. A study showed that in general hospitals more than $30 \%$ of individuals on acute medical wards lack capacity to consent to treatment. ${ }^{9}$ A recent study revealed that a third of people admitted to old age psychiatry wards fell into the 'Bournewood gap'.10 Another study revealed that $44 \%$ of psychiatric in-patients lack treatment-related decisional capacity and out of these $17 \%$ fell in the 'Bournewood gap..11 We are currently not aware of any similar study in learning disability psychiatric in-patient units but it is expected that the number of incapacitated patients admitted informally would be higher compared with other specialties.

\section{Conclusion}

The Mental Capacity Act 2005 is in its first year of operation. Given the nature of the patient group learning disability psychiatrists deal with, the expectation will be that they need to be conversant with the basic principles that underpin the Act. Our survey clearly demonstrates that respondents are still unsure about important aspects of the Act, which might have serious legal implications. Although the modest sample size is a limitation of our survey, we have no reason to believe our respondents were an atypical group.

The adequacy of training of professionals in the Mental Capacity Act needs to be more systematically assessed. Training issues regarding various aspects of the new Act with special emphasis on assessment of capacity and knowledge about the Code of Practice may well need to be implemented in a similar way as it is done for the existing Mental Health Act 1983 (Section 12 Approval).

Clearly the Act provides safeguards for vulnerable people. It empowers people to make decisions for themselves when possible and protects people who lack capacity to do so. However, implementing the Act in dayto-day clinical practice will have implications on the workload of professionals, which needs to be addressed.

\section{Declaration of interest}

None.

\section{References}

1 Department of Constitutional Affairs. Mental CapacityAct 2005 Code of Practice. TSO (The Stationery Office), 2007.

2 L v. Bournewood Community and Mental Health NHS Trust [1998] 2 WLR 764.

3 HL v. UK, European Court of Human Rights, C[2004] ] 4269

4 Department of Health. Mental CapacityAct 2005: Deprivation of Liberty Safeguards. Deparment of Health, 2007 (http://www.dh.gov. uk/en/Consultations/ Liveconsultations/DH.078052).

5 British Medical Association. The Mental CapacityAct 2005 Guidance for health professionals. BMA, 2007.

6 Evans K, Jackson E, Warner J. How much do emergency healthcare workers know about capacity and consent? Emerg Med J 2007: 24; $391-3$

7 Jackson E, Warner J. How much do doctors know about consent and capacity? J R Soc Med 2002; 95 601-3.

8 Ranjith G, Hotopf M. 'Refusing treatment - please see': an analysis of capacity assessments carried out by a liaison psychiatry service. JR Soc Med 2004; 97; 480-2.

9 Raymont $\mathrm{V}$, BingleyW, Buchanan A, David AS, Hayward P, Wessely S, et al. Prevalence of mental incapacity in medical inpatients and associated risk factors: cross-sectional study. Lancet 2004; 364; 1421-7.

10 Singhal A, Kumar A, Belgamwar RB, Hodgson RE. Assessment of mental capacity: who can do it? Psychiatr Bull 2008; 32, 17-20.

11 Cairns R, Maddock C, Buchanan A, David AS, Hayward P, Richardson G, et al. Reliability of mental capacity assessments in psychiatric inpatients. BrJ Psychiatry 2005; 187, 372-8.

*Indermeet Sawhney Consultant Psychiatrist, North East Essex PCT, Heath House, Colchester C02 8GU, email:indermeet.sawhney@neessexpct.nhs.uk, Abir Mukhopadhyay Specialist Registrar, North East Essex PCT,

Colchester, Chuda Karki Clinical Director, North East Essex PCT, Braintree, Essex 